\title{
Model Based Indirect Conicity Estimation Technique for Solid Axle Railway Wheelset
}

\author{
Erum Saba' ${ }^{1}$ Imtiaz Hussain Kalwer ${ }^{2}$, Mukhtiar Ali Unar ${ }^{1 b}$ \\ RECEIVED ON 11.04.2020, ACCEPTED ON 20.12.2020
}

\begin{abstract}
Conicity is an important characteristic that helps the railway vehicle to steer itself down the track. However during the operation, the conicity tends to change inconsistently due to frictional contact at the wheel-rail interface. Safety, reliability and ride comfort which are utmost importance for journey are adversely affected due to the changes in conicity level beyond certain limit. Several techniques have been employed for monitoring the health of the railway wheelset however still a significant potential exists to investigate the wheelset conicity. This paper presents a model based technique to monitor the wheelset condition which contributes to the wheel flats due to decrease in conicity level and the problem of false flanges due to increased level of conicity. In this paper an unconstrained solid axle railway wheelset is considered for study. The dynamic behavior of the wheelset is analyzed at different conicity levels to understand the effect of the conicity on the wheelset. In order to demonstrate the potential of this research work a simulation model is developed in Matlab/ Simulink to mimic the behavior of an actual wheelset. Simplified linearized model of the wheelset is used to estimate the dynamics of the wheelset. From the simulation results it is evident that the frequency of vibration is changing with the changes in conicity level. In this way using the proposed method the conicity level is indirectly identified. The results produced by simulation model are satisfactory.
\end{abstract}

Keywords: Railway Wheelset, Model Based Approach, Conicity

\section{INTRODUCTION}

$\mathrm{T}$ The railway wheelset is a vital element in railway transport because it not only provides the traction and body suspension but also steers the vehicle down the track. Unlike road vehicles the railway wheelset provides guidance and steering ability therefore its structure is completely different from the tires of the road vehicles (Fig. 1). The major difference in the structure of the tire of road vehicle and the railway vehicle is the wheel tread. The tread of the railway wheelset is not only conical but also both the wheels are rigidly fixed on a common axle. Both rigidly fixed structure of the railway wheelset and the conical wheel tread provide the natural steering ability on straight and curved tracks. The flanges are mounted on the inner side of the wheelset to prevent the derailment in case of large accidental lateral displacement $[1,4,7,9,10,13,14]$.

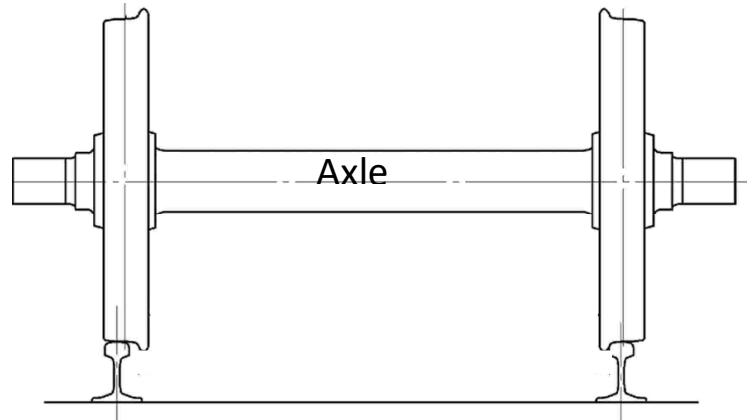

Fig. 1: Railway Wheelset [22]

\footnotetext{
${ }^{1}$ Institute of Information and Communication Technologies, Mehran University of Engineering and Technology, Jamshoro, Sindh, Pakistan.

Email: aerumimranali@gmail.com (Corresponding Author), bmukhtiar.unar@ faculty.muet.edu.pk

${ }^{2}$ Department of Electrical Engineering, DHA Suffa University, Karachi, Sindh, Pakistan.

Email: imtiaz.hussain@dsu.edu.pk
}

This is an open access article published by Mehran University of Engineering and Technology, Jamshoro under CC BY 4.0 International License. 
On the straight track, if the wheelset is laterally displaced to left or right the difference in rolling radii is created. Both the wheels have the same rotational velocity because both are rigidly fixed to common axle [1]. Because of this the wheelset is forced to yaw which in turn aligns the wheelset back to the centre position naturally [16].

The conicity is the characteristic that describes the wheel's tendency to roll like a cone [2]. This tendency helps the steering performance of the vehicle. The conicity is the major factor which allows the railway wheelset to run on the straight and curved tracks without flange contact [3]. But during the operation conicity tend to change inconsistently due to frictional contact at the wheel-rail interface $[4,18]$.

Therefore it is important to maintain certain conicity level on the wheel tread otherwise the vehicle's natural guidance and steering ability will be lost, which may result in negative influence on passenger comfort and causes annoyances to nearby residents due to increased noise and vibration levels and eventually derailment.

Several signal and model based techniques have been employed in the railway condition monitoring systems $[1,6,8,11,12,16,17,20]$. Most of these techniques are applied to monitor the condition of railway suspension system or wheel-rail adhesion [14]. Unfortunately still a small amount of work has been carried out to monitor the wheel conicity. Therefore, a significant room exists to explore and monitor the wheel flats due to decrease in conicity level and the problem of false flanges due to increase level of conicity. This research work would be one step forward in this direction.

This paper is a part of the research that uses multiple model based estimation approach for the identification of wheelset conicity. The paper is organized in the following manner. After discussing the preliminaries in section 1, section 2 deals with wheelset dynamics followed by section 3 discussing model based estimation. Section 4 then gives the results and discussion of the work regarding estimation of wheelset conicity. The last section is about conclusion and future work.

\section{RAILWAY WHEELSET DYNAMICS}

In this research work a single unconstrained solid axle wheelset is considered to demonstrate the potential of the proposed idea. Other similar studies [1, 2, 4, 8, 12, $15,19]$ suggest that the only lateral dynamics are sufficient for demonstration of the proposed idea. Thus when the wheelset is moved laterally, the wheelset oscillates about the vertical axis as shown in Fig. 2. The difference in radius also causes the wheelset to cover more distance along one direction than the other but the yaw angle forces the wheelset to align back into the center position. The wheelset thus exhibits sustained oscillation in the lateral plane, that quantifies to lateral acceleration linked to the concept of conicity, a phenomenon known as wheelset hunting.

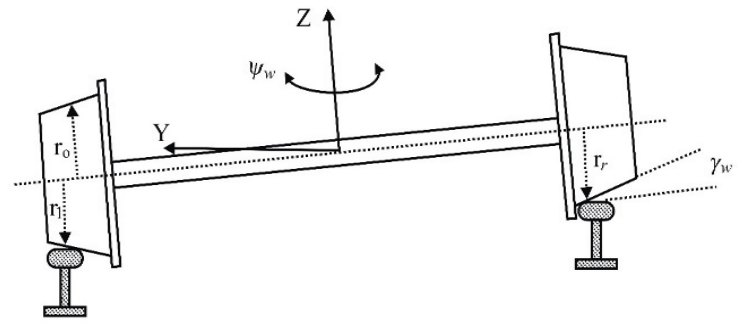

Fig. 2: Railway Wheelset Lateral Displacement [1]

The proposed idea is based on the fact that an unconstrained wheelset exhibits kinematic oscillations at non-zero speeds. The frequency of oscillation is given by the Klingel's formula [11], which relates the wheelset conicity $\lambda_{w}$, the frequency $f$, the lateral distance between wheels and rails $\mathrm{L}_{\mathrm{g}}$ and wheel radius $\mathrm{r}_{\mathrm{o}}$.

$\mathrm{f}=\frac{\mathrm{Vs}}{2 \pi} \sqrt{\frac{\lambda_{\mathrm{w}}}{\mathrm{Lg}_{\mathrm{g}}}}$

Creep forces have a significant impact on the dynamics of the wheelset occurring when there is a difference between the relative speeds of the wheel and the rail. This force exhibits its presence when wheel deviates from pure rolling especially when the wheelset is subject to lateral forces, some forces tangential to the normal forces are transmitted to the rail at the contact patch [1].

Thus the creep forces have a direct effect on the yaw 
and lateral dynamics and thus the total creep force in the lateral direction is given by;

$$
\mathrm{m}_{\mathrm{w}} \ddot{\mathrm{y}}_{\mathrm{w}}=-\mathrm{F}_{\mathrm{yR}}-\mathrm{F}_{\mathrm{yL}}
$$

where $\mathrm{F}_{\mathrm{yR}}, \mathrm{F}_{\mathrm{yL}}$ are the right and left wheel creep forces, in lateral direction, $m_{w}$ is the mass of wheelset and $\ddot{y}_{w}$ is the lateral acceleration of the wheelset.

Longitudinal creep of left wheel is given as

$\gamma_{\mathrm{xL}}=\frac{\mathrm{L}_{\mathrm{g}} \psi_{\mathrm{w}}}{v_{v}}+\frac{\lambda_{\mathrm{w}}\left(\mathrm{y}_{\mathrm{w}}-\mathrm{y}_{\mathrm{t}}\right)}{\mathrm{r}_{0}}$

where $\mathrm{L}_{\mathrm{g}}$ is the track half gauge, $\psi_{\mathrm{w}}$ is the yaw rate of the wheelset, $\lambda_{\mathrm{w}}$ is the wheelset conicity, $\mathrm{v}_{\mathrm{v}}$ is the vehicle forward speed, $y_{w}$ is the lateral displacement, $y_{t}$ is the track disturbance and $r_{o}$ is the wheel radius.

Lateral creep of left wheel is given as

$\gamma_{\mathrm{yL}}=\frac{\mathrm{y}_{\mathrm{w}}}{v_{\mathrm{v}}}-\psi_{\mathrm{w}}$

where $y_{\mathrm{w}}$ is the lateral velocity of the wheelset, $\psi_{\mathrm{w}}$ is the yaw movement of wheelset and $v_{v}$ is the vehicles forward speed.

The yaw movement is also a cause of creep forces in opposite directions for the two wheels as given by;

$\mathrm{I}_{\mathrm{w}} \ddot{\Psi}_{\mathrm{w}}=\mathrm{F}_{\mathrm{xR}} \mathrm{L}_{\mathrm{g}}-\mathrm{F}_{\mathrm{xL}} \mathrm{L}_{\mathrm{g}}-\mathrm{k}_{\mathrm{w}} \psi_{\mathrm{w}}$

where $\mathrm{k}_{\mathrm{w}}$ is the measure of stiffness of the yaw spring, $I_{w}$ is the moment of inertia of wheelset and $\mathrm{F}_{\mathrm{xR}}$ and $\mathrm{F}_{\mathrm{xL}}$ are creep forces in longitudinal directions.

A simulation model is developed using a simplified mathematical model to simulate the behavior of the railway wheelset. Parameter values used in this work for the wheelset modelling are listed in Table 1.

\section{MODEL BASED ESTIMATION}

In this research a model based technique is proposed to monitor the condition of the railway wheelset conicity by analyzing the variations in the dynamic response of the wheelset. Vehicle guidance forces generated at wheel rail contact patch depend upon several factors including adhesion level on tracks, the degree of wheel/rail lubrication, track curvature and the detailed transverse profile shapes of the wheels and rails [5]. However as mentioned above the lateral dynamics are sufficient to estimate the system states using some monitoring technique.

\begin{tabular}{|c|c|c|}
\hline \multicolumn{3}{|c|}{$\begin{array}{c}\text { Table 1: Parameter Values Used in Wheelset } \\
\text { Model }\end{array}$} \\
\hline Parameter & Description & Value \\
\hline $\mathrm{m}_{\mathrm{w}}$ & $\begin{array}{l}\text { Mass of the wheelset } \\
(\mathrm{kg})\end{array}$ & 1250 \\
\hline$v_{v}$ & Vehicle speed $(\mathrm{m} / \mathrm{s})$ & 30 \\
\hline $\mathrm{r}_{\mathrm{o}}$ & $\begin{array}{l}\text { Rolling radius of the } \\
\text { wheels at centre } \\
\text { position }(\mathrm{m})\end{array}$ & 0.5 \\
\hline $\mathrm{I}_{\mathrm{w}}$ & $\begin{array}{l}\text { Yaw moment of inertia } \\
\text { of the wheelset }\left(\mathrm{kg} \mathrm{m}^{2}\right)\end{array}$ & 700 \\
\hline $\mathrm{k}_{\mathrm{w}}$ & Yaw stiffness (N/rad) & $5 \times 10^{6}$ \\
\hline$\lambda_{\mathrm{w}}$ & $\begin{array}{l}\text { Conicity of the wheel } \\
\text { tread }\left(\lambda_{w}\right)\end{array}$ & Variable \\
\hline $\mathrm{L}_{\mathrm{g}}$ & Track half guage (m) & 0.75 \\
\hline
\end{tabular}

Model based estimation is a type of technique that uses some knowledge of the system of interest to establish its current condition as shown in Fig.3.

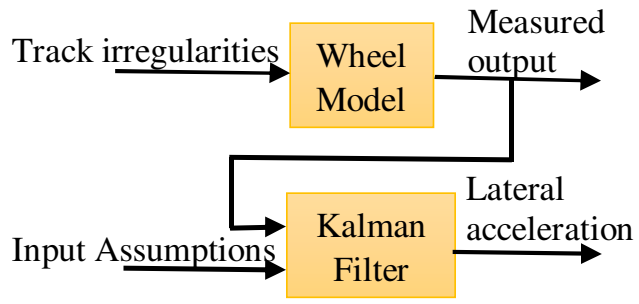

Fig. 3: Railway Vehicle Condition Monitoring

Track irregularities are the main excitation mechanism in the track vehicle dynamics system which are generally interpreted as the deviations from design geometry [12]. The four track irregularities defined in literature are longitudinal level irregularities, alignment irregularities, cross level irregularities and the track gauge irregularities [21]. Thus the track irregularities modeled as transfer function representing actual frequencies generated upon wheel rail contact are used which serves as input to the model [1].The measured output of the system is fed to the condition monitoring strategy alongwith some input 
assumptions $[12,20]$. In this work Kalman filter is used to produce an estimate of system parameters. The lateral acceleration which is one of the estimation results is then taken into further processing to find the actual conicity of the wheelset.

Kalman filter is used in our model because the wheel rail contact produces a situation where noise significantly overwhelms the useful data. Furthermore Kalman filter becomes a very useful candidate when the variables of interest can only be measured indirectly making it more suitable tool for an indirect estimation of wheel conicity. Thus the estimator is tuned to operate in a way imitating the wheelset itself. The lateral dynamics including the lateral velocity and yaw rate are fed to the estimator .The estimator produces a good estimate of the lateral acceleration producing small error when compared with the lateral acceleration of the wheelset model thereby indirectly estimating the conicity of the wheelset.

\section{RESULTS AND DISCUSSIONS}

After developing wheelset model in Matlab the next step was to develop an estimation of the lateral acceleration in Matlab and compare it with the lateral acceleration of the actual wheelset model as shown in Fig. 4. Yaw rate and lateral velocity are measured which serves as an input to the Kalman filter alongwith sensor noise. Here for different conicity values the actual and estimated values are calculated and compared. Results in time scope and frequency analysis showing eigen value migration are shown.

The simulation model is based on unconstrained wheelset resulting in lateral acceleration by the wheelset. The frequency of oscillations can be calculated by using Klingel's formula given in equation (1).

If all other parameters in equation (1) are kept constant then the frequency of oscillation will only depend upon conicity of the wheelset. Therefore, the simulations are carried out at different conicity levels and the results of simulation are given below.

The selection of conicity values used in this paper is not arbitrary as the literature review suggests a range of values from 0.01 to 0.3 which indicates the state of wheelset including wheel flats, false flanges and when operating in normal condition. Fig. 5 shows the lateral acceleration of unconstrained wheelset when conicity level is very low at 0.05 . The figure also shows that the estimated lateral acceleration closely matches the actual lateral acceleration obtained from wheelset model, both operating on same conicity, producing a small error. If the conicity is further decreased the frequency of oscillation is also decreased. Decreasing conicity below 0.05 means the wheel tread is worn out and has almost become cylindrical in shape. Cylindrical wheel tread do not have the tendency to align itself back at the center position. Therefore it is necessary in proper operation of railway that the certain conicity level is maintained to ensure safe and comfortable operation of railway transport.

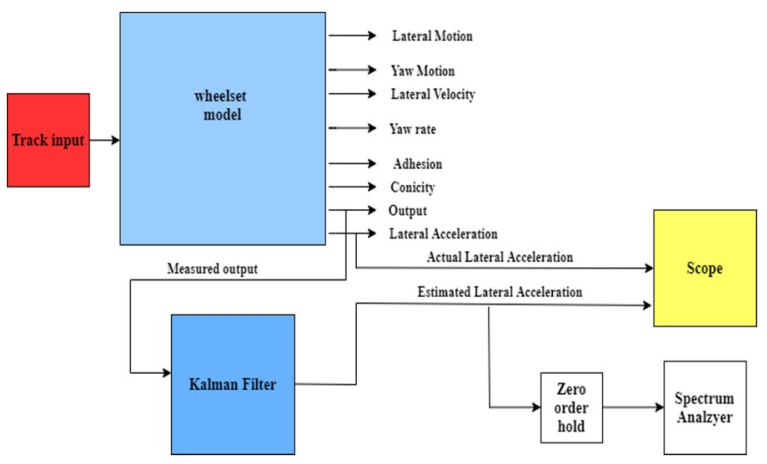

Fig. 4: Simulink Model
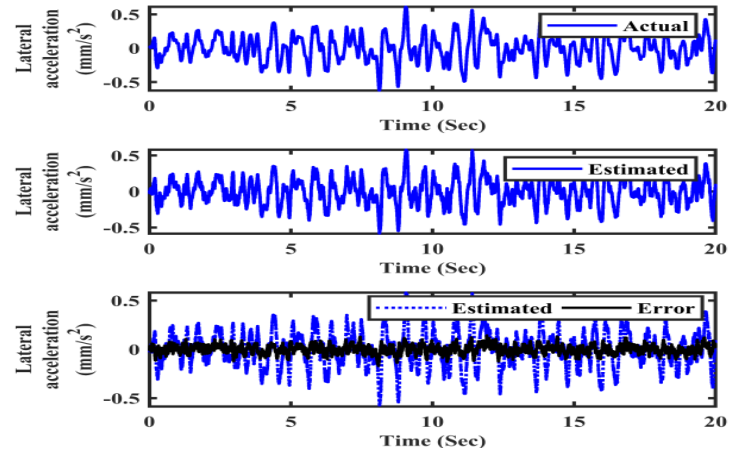

Fig. 5: Lateral Acceleration of Unconstrained Wheelset $\left(\lambda_{\mathrm{w}}=0.05\right)$

In Fig. 6 conicity is increased to 0.15 which is reflected in the increase in lateral acceleration. Fig. 7 to Fig. 9 shows lateral acceleration results where conicity is kept as $0.2,0.25$ and 0.3 respectively. As the conicity level is increased beyond 0.2 , high frequency vibrations are produced as given in Table 2 which may 
cause discomfort to passengers, permanent mechanical component failure and huge noise as the train passes along the track.
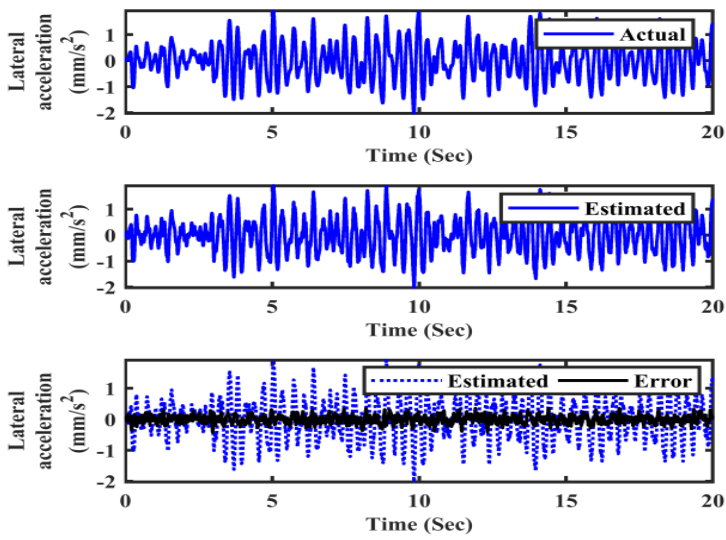

Fig. 6: Lateral Acceleration of Unconstrained Wheelset $\left(\Lambda_{\mathrm{W}}=0.15\right)$
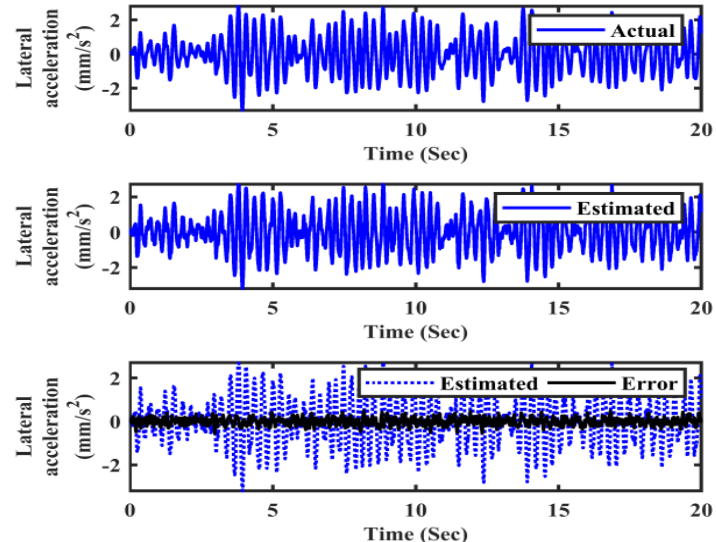

Fig. 7: Lateral Acceleration of Unconstrained Wheelset $\left(\lambda_{\mathrm{w}}=0.2\right)$
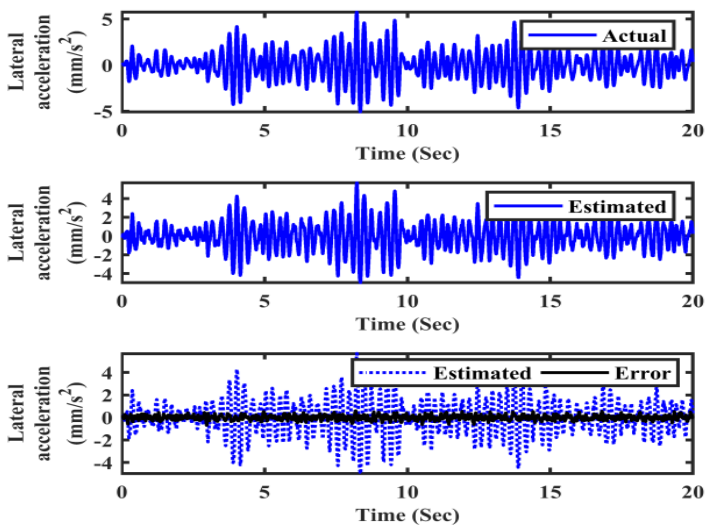

Fig. 8: Lateral Acceleration of Unconstrained Wheelset $\left(\lambda_{\mathrm{w}}=0.25\right)$
It may be observed that the residual or error between the actual lateral acceleration and the estimation is trivial thereby strengthening the case for our argument that the model based estimation produces lateral acceleration that mimics the lateral acceleration for wheelset model. This trend could be observed in all results given in Fig. 5 to Fig. 9 for different values of conicity.
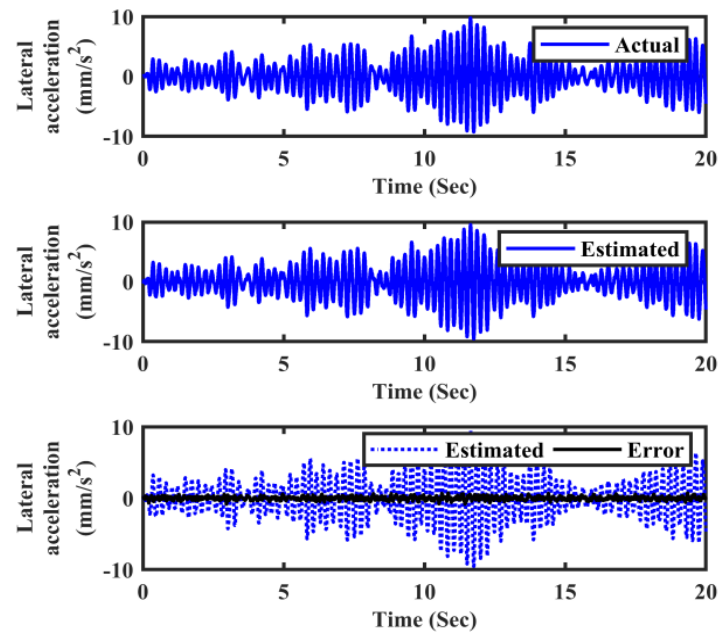

Fig. 9: Lateral Acceleration of Unconstrained Wheelset $\left(\lambda_{\mathrm{w}}=0.3\right)$

It could be observed that the estimated lateral acceleration tends to match the actual lateral acceleration obtained from the wheelset model. For different conicity values similar trend is observed thus the estimator operating on a certain conicity produces lateral acceleration which closely matches the actual lateral acceleration obtained from the system. In real scenario the actual lateral acceleration would be obtained from accelerometer without knowing the conicity whereas the estimator produces a closely matched value of lateral acceleration thereby indirectly finding the conicity.

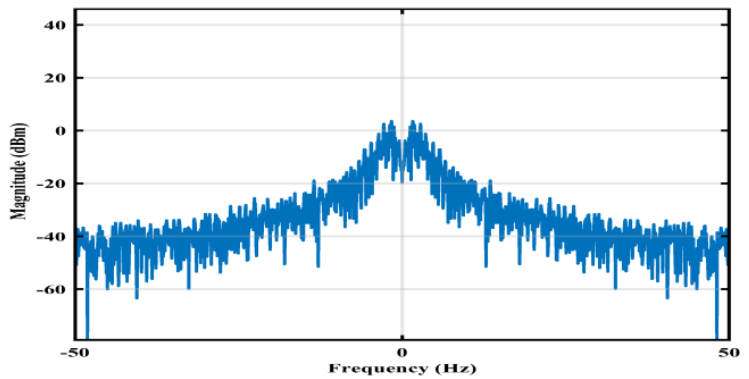

Fig. 10: Spectrum Analysis at Conicity 0.05 
Fig. 10 shows the strength of the signal against the frequencies when conicity is 0.05 which is obtained using spectrum analyzer in Simulink employing the Welch method. The peak value is obtained at $1.63 \mathrm{~Hz}$ with a magnitude of $3.629 \mathrm{dbm}$. When conicity is increased to 0.1 the peak value reaches to $2.8 \mathrm{~Hz}$ with magnitude of $13.092 \mathrm{dbm}$ and reaches to $4.23 \mathrm{~Hz}$ when conicity becomes 0.3 with a magnitude $33.368 \mathrm{dbm}$. The other frequencies are given in Table 2 for all the conicity values used in this paper under investigation. The increasing frequency suggests that varying conicity causes changes in signal strength due to changing lateral dynamics. The low frequency results also suggest that these frequencies exhibit the kinematic mode excited by lateral dynamics as expected.

\begin{tabular}{|c|c|}
\hline \multicolumn{2}{|c|}{ Table 2: Conicity vs Frequency Values } \\
\hline Conicity & Frequency(Hz) \\
\hline 0.05 & 1.63 \\
\hline 0.1 & 2.80 \\
\hline 0.2 & 3.58 \\
\hline 0.25 & 3.78 \\
\hline 0.3 & 4.23 \\
\hline
\end{tabular}

The analysis of wheelset dynamics could be also explored using eigen value analysis which provides an in-depth view of the system by observing characteristics such as frequency of oscillations and damping. The dynamic behaviour of the railway wheelset varies if the vehicles speed, contact conditions and yaw stiffness are varied. The eigen value migration for kinematic mode at velocity $30 \mathrm{~m} / \mathrm{s}$ and yaw stiffness $5 \times 10^{6}(\mathrm{~N} / \mathrm{rad})$ are given in Fig. 11 for different values of conicity.

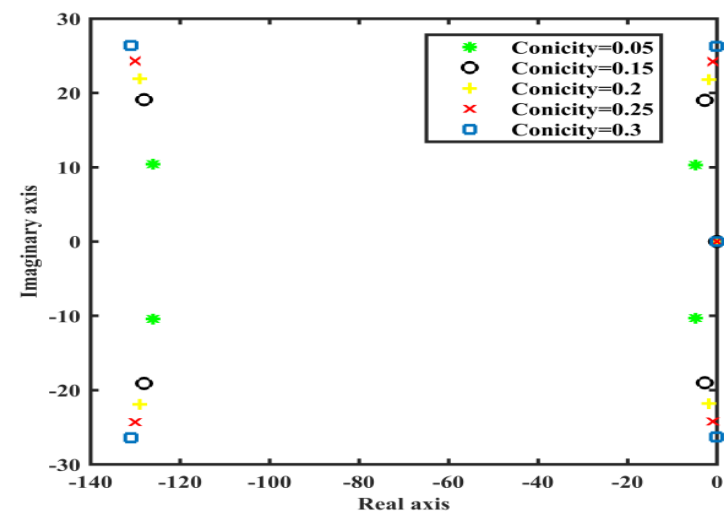

Fig. 11: Eigen Value Migration for Different Values of Conicity
Fig.11 clearly indicates that as the conicity of the wheelset is varied the frequency of lateral dynamics is also increased. This research work was based on the exploitation of this phenomenon to identify the wheelset condition from frequency of lateral dynamics.

\section{CONCLUSION AND FUTURE WORK}

The increasing use of railways both for passenger and commercial purposes has put immense pressure on modern railway transport to increase the safety and reliability of the transport. Plenty of research work is being carried out to resolve the issues related to maintenance of the railway wheelset. Results both in time and frequency suggest that the varying conicity have a direct relationship with lateral acceleration and any means to measure the lateral acceleration could be used as a means for finding the conicity which gives idea about the health of the wheelset In this paper a new method is proposed to indirectly measure the conicity of the wheelset. The presented results show great agreement with the proposed idea.

However, the work presented here is a preliminary research work. Further modifications are possible to improve the simulation results by considering the complete bogie model. From the simulation results it is evident that the wheelset dynamics are changing with the changes in conicity level. Therefore single Kalman filter is not sufficient to estimate the wheelset parameters in all conditions. A bank of Kalman filter tuned to operate at different conicity levels will be designed in future to estimate the wheelset dynamics at different conicity condition. Actual conicity condition then can be identified using best match approach employing fuzzy logic or even considering machine learning and deep learning strategies.

\section{ACKNOWLEDGEMENT}

The valued comments and suggestions from members of the research group at the National Centre of Robotics and Automation (NCRA) Mehran University of Engineering and Technology (MUET) Jamshoro, Pakistan are highly acknowledged. 


\section{REFERENCES}

1. Hussain I., "Multiple Model Based Real Time Estimation of Wheel-Rail Contact Conditions" PhD Thesis, University of Salford, Manchester UK, 2012.

2. Bernal E., Spiryagin M., Cole C., "Onboard Condition Monitoring Sensors, Systems and Techniques for Freight Railway Vehicles: A Review", IEEE Sensors Journal, Vol. 19, No. 1, pp. 4-24, 1 Jan.1, 2019

3. Li P., Goodall R., "Model Based Condition monitoring for railway vehicle systems", Proceedings of the UKACC International Conference on Control, University of Bath, UK, Sep 2004.

4. Kraft S., Causse J., "An approach for the validation of railway vehicle models based on track measurement", International Journal of Vehicle Mechanic and Mobility, Vol. 53, No. 10, 2015.

5. Firlik B., Czechyra B., Chudzikiewicz A., "Condition monitoring system for light rail vehicle and track", Key Engineering Materials, Vol. 518, pp. 66-75, 2012.

6. Hubbard P., Ward C., Dixon R., Goodall R., "Real time detection of low adhesion in the wheel/rail contact", Proceedings of the Institution of Mechanical Engineers, Part F: Journal of Rail and Rapid Transit, Vol. 227, No.6, pp. 623-634, 2013.

7. Wickens A., "The dynamics of railway vehiclesfrom Stephenson to Carter", Proceedings of the Institution of Mechanical Engineers, Part F: Journal of Rail and Rapid Transit, Vol. 212, No.3, pp. 209-217, 1998.

8. "Wheel/Rail Profile Maintenance", Kevin J. Sawley Transportation Technology Center, Inc., Pueblo, Colorado, Identification No. 461, 2016.

9. Mei T.X., Goodall R.M., "Practical Strategies for Controlling Railway Wheelsets Independently Rotating Wheels", Journal of Dynamic Systems, Measurement, and Control, Vol. 125, No.3, pp. 354-360, 2003.

10. Knothe K. BÃhm F., "History of Stability of Railway and Road Vehicles", Vehicle System Dynamics, Vol. 31, No.5, pp. 283 - 323, 1999.
11. Alemi A., Corman F., Lodewijks G., "Condition monitoring approaches for the detection of railway wheel defects", Proceedings of the Institution of Mechanical Engineers, Part F: Journal of Rail and Rapid Transit, Vol. 231, No. 8, pp. 961-981, 2017.

12. Charles G., Goodall R., Dixon R., "Model-based condition monitoring at the wheel-rail interface", Vehicle System Dynamics, Vol. 46, No. Sup 1, pp. 415-430, 2008.

13. Bracciali, "Railway wheelsets: History, Research and Developments", International Journal of Railway Technology, Vol. 5, No. 1, pp. 23-52, 2016.

14. Liu X. Y., Alfi S., Bruni S., "An efficient recursive least square based condition monitoring approach for a rail vehicle suspension system", Vehicle System Dynamics, Vol. 54, No. 6, pp. 814-830, April 2016.

15. Bosso N., Gugliotta A., Zampieri N., "Design and testing of an innovative monitoring system for railway vehicles," Proceedings of the Institution of Mechanical Engineers, Part F: Journal of Rail Rapid Transit, Vol. 232, No. 2, pp. 445-460, October 2016.

16. Vale C., Bonifacio C., Seabra J., Calcada R., Mazzino N., Elisa M., Terribile S., Anguita D., Fumeo E., Saborido C., Vanhonecker T., De Donder E., Laeremans M., Vermeulen F., Grimes D., "Novel efficient technologies in Europe for axle bearing condition monitoring-The MAXBE project", Transport Research Procedia, Vol. 14, pp. 635-644, June 2017.

17. Li C., Luo S., Cole C., Spiryagin M., (2017). “An overview: modern techniques for railway vehicle on-board health monitoring systems," Vehicle System Dynamics, Vol. 55, No. 7, pp. 1045-1070, 2017.

18. Onat A., Voltr P., Lata M., "A new friction condition identification approach for wheel-rail interface", International Journal of Rail Transportation, Vol. 5, No. 3, pp. 127-144, 2017.

19. Hassan M., Bruni S., Carboni M., "Crack detection in railway axle using horizontal and vertical vibration measurements", Proceedings of the 7th IET Conference on Railway Condition Monitoring (RCM 2016), Birmingham, 2016, pp. $1-6,2016$. 
20. Chudzikiewicz A., Bogacz R., Kostrzewski M., Konowrocki R., "Condition monitoring of railway track systems by using acceleration signals on wheelset axle-boxes", Transport, Vol. 33, No. 2, pp. 555-566, 2018.

21. Karis T., "Correlation between Track Irregularities and Vehicle Dynamic Response Based on Measurements and Simulations", Thesis KTH, Stockholm, Sweden, 2018.

22. European railway agency report available at www.era.europa.eu/sites/default/files/library/doc s/recommendation/era_ertms_033281_technical_ document_en.pdf (Accessed on 05-08-2019) 